blood. The genital organs show an extraordinary difference between male and female; the male being provided with large and powerful clasping apparatus. The legs of the fly are long, hairy, and provided with a terminal hook, which enable it to hold on and obtain purchase for driving in its proboscis. The proboscis of the male is somewhat shorter than that of the female. The fly rans quickly, and is possessed of much intelligence in hiding or endeavouring to escape. The female phlebotomus bites. It is not certain at present whether the male does or not. The flies are usually to be found in pairs.

\section{Preventive Treatment.}

Human and other excrement should be destroyed or buried. Latrines should be sprayed with paraffin twice in a week. Although the fever does not tend to a fatal termination, the sequelae may be troublesome or even serious, and there is no doubt that it incapacitates a considerable percentage of the population.

The clinical observations have been made upon a number of cases, and confirmed by observations upon myself. I have a peculiar attraction for these flies. Last year, after a sea voyage, and when in the best of health, after carefully excluding the possibility of bites from other insects, I was bitten by six of these flies. Within forty.eight hours symptoms set in and followed the usual course.
I much regret that, owing to an accident, my experiments in breeding the flies were brought to a premature close. I hope, however, to continue them shortly.

I append a description of the fly, kindly sent to me by Mr. Newstead, of the Liverpool School of Tropica Medicine.

The members of the genus Phlebotomus may bo recognized by the following characteristics: Small hairy flies; thorax humped, wings long and narrow with ten veins, all of which, including the costal vein and hind margin, are olothed with long hairs. There are no cross veins as in mosquitos or other allied flies, and the veins are never clothed with scales. Legs long and slender. Antennae setose of fifteen segments in male Palpi of four segments. Proboscis twice the length of the head, consists of mandibles, maxilla, labrum, labium, and hypopharynx. The buccal organs of the male are shorter than those of the female; the colour is a light brown with hardly any variation.

I much regret that I have been unable to read the recent publications of Drs. K. Franz and Taussig on this subject.

Treatment.

This is symptomatic, there being no specific. When the digestion improves, iron and arsenic are useful to combat the resultant anaemia.

\section{SKIAGRAMS OF MULTIPLE RENAL CALCULI AND OF FRACTURES DUE TO MUSCULAR VIOLENCE. BY \\ OWEN L. RHYS, M.D.}

MEDICAL OFFICER, FLECTRICAL DEPARTMENT, CARDIFF INFIRMARY.

The two skiagrams illustrated were obtained with exposures of two minutes, no compression being used, and the breathing being natural. The print showing tha renal calculi is of special interest to radiographers, inasmuch as the sma]l calculi were 80 clearly defined, in spite of the movements of the dia. phragm, that 27 of the 28 stones found at the operation could be counted on the plate. In this, and in many other cases, an exact outline of calcali has been obtained by exposures of about two minutes, and though in some subjects the kidney was abnormally well fixed, in others where the condition was not of long standing there was practically no movement of the kidney.

Case I.

This skiagram is of the kidney regions of a middleaged collier, who was under the care of Mr. William Sheen at Cardiff Infirmary. In the right kidney Mr. Sheen found the large calculus seen in the print and twenty-eight small faceted stones. The large calculus weighed $123 \frac{1}{2}$ grams, and measured $7 \mathrm{~cm}$ in its longest and $5.4 \mathrm{~cm}$. in its shortest diameter; it had an almost smooth surface. In the left kidney there was a single stone, about as large as a pigeon's egg. All were phosphatic deposits
The print does not show another interesting appearance which is easily seen on the plate, and which is also seen in the skiagram of Case II. This is an apparent separation of half of the right transverse process of the first dorsal vertebra. This man had had no injury to the back.

\section{CASE II.}

This man was a collier, aged 32 , who strained his back five years ago. The strain was caused by,his lifting a tram of coal off his mate, who had fallen below it. He lifted this weight with his hands behind him underneath the tram, and his back against its side, and remained for some time sup. porting the woight until belp axrived. He walked home, and worked for some days afterwands, but ever since has complained of pain in the left loin, and has not been able to do very heavy work. I took a skiagram of his left loin some months ago, when renal calculus was suspected, but did not notices any abnormality. He lately came to the out-patient department under Dr. Herbert Cook, and was again radiographed for stone. This plate showed both kidney regions clear, but severat fractures of the right transierse processes of the lumbar vertebrae. The second, third,
bases and lying and fourth are separated from their bases and lying
far below, and external to their normal position, though far below, and external to their normal position, though the processes remain blunt, while the inner ends of the separated part are thinned, or appear so in the plate. The tip of the fifth right transverse process. has also been separated, but not displaced.

This man had received no blow, so that the fractures axe 
apparently due to excessive action of the psoas magnus and quadratus lumborum muscles.

I have not heard of a similar case, nor can I find an explanation of the fact that all the pain complained of is

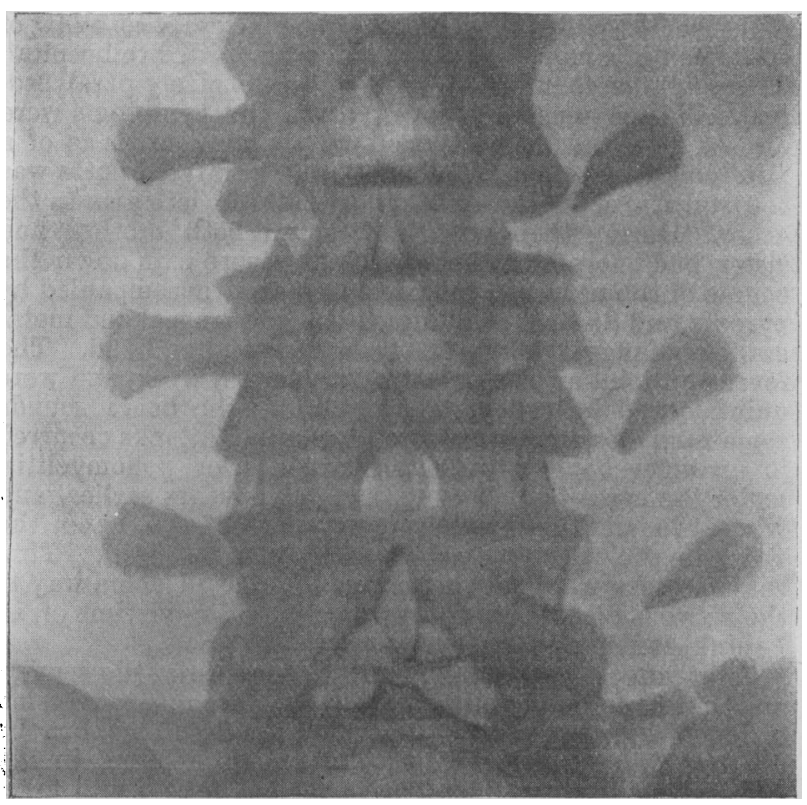

CASE Ir.-Two-minute exposure. Shows fracture of right transverse processes of second, third, lourth, and fifth lumbar vertebrae due to muscular violence.

on the left side. This latter fact partly explains why the ractures were not noticed previously, as the plate taken some months ago shows the condition very faintly, but the opposite side was the more minutely examined.

\section{SEVENTY.EIGHTH ANNUAL MEETING} OF THE

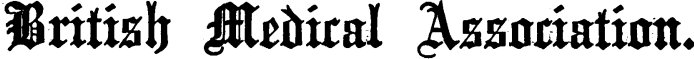

Feld in London on July 22nd, 23rd, 25th, 26th, 27th, 28th, and 29th.

PROCEEDINGS OF SECTIONS.

\section{SECTION OF DISEASES OF CHILDREN.}

Archibald E. Garrod, M.D, F.R S., President.

\section{PRESIDENT'S INTRODUCTORY REMARKS.}

Dr. Garrod initiated the proceedings by a few observa. tions on the peculiar interest and importance of a study of the phenomena of disease in children; he then drew attention to the subjects which had been selected for special discussion, and declared the session open.

\section{DISCUSSION}

\section{ON THE DIAGNOSIS AND TREATMENT OF NON-TUBERCULOUS JOINT DISEASES IN CHILDREN.}

\section{OPENING PAPERS}

I.-J. A. Coutrs, M.B.Cantab., F.R.C.P.

Tre diseases of the joints in children are the same as those occurring in adults, however much they may differ in the younger subjects in frequency of incidence, severity, and consequences. Their very number, then, must prohibit me from dealing with any single one at any length, and the utmost in my power is to select some of the more salient points of the more important ones that may suggest themselves as suitable for discussion.

Amongst the joint complaints of children those due to rheumatism hold the foremost place. They are the first in importance, not from any local severity of their own, but from their numerical frequency and their association with serious heart lesions. There are few other joint diseases in children, too, that are not apt to be mistaken for rheumatism in some of their phases, and differentiation from the last plays an important part in the diagnosis of most.

The mildness of the rheumatic joint affections often leads to their being neglected or missed by parents and nurses, and it is a common experience that in many a case of serious cardiac mischief it is oply close inquiry that calls up the memory of growing pains, slight limping, or some such history in the past. Although never excessive in young children, the severity of the joint affections varies between narrow limits, and I would state that, in my opinion, in the younger subjects the frequency of heart complications is in some degree proportional to the extent and severity of the arthritis. In children under the age of 7 , for example, where the rheumatism is so definite as to cause obvious joint swelling, it is exceptional, in m experience, for the heart to escape. In older children, and especially towards the age of puberty, the joint lesions take on the more severe and painful form of the adult type of the complaint.

The mildness of the joint symptoms in average cases has led, I believe, to an under-estimation of their frequency, even on the part of members of the profession. Not in frequently one hears of cases of rheumatism in children where endocarditis or pericarditis is described as the primary and sole manifestation of the disease, as the disease in fact, and where it is confidently assumed and asserted that no joint symptoms had at any time existed. I would only state that in my experience cases of unequivocal rheumatism are extremely rare where adequate inquiry does not reveal a history of some degree of joint pain, however slight and evanescent the last may have been. Even in cases starting with such a painfal affection as acute tonsillitis the joint pains are ordinarily present, although they may be obscured by those of the more prominent disorder. Slight and evanescent, then, as thes often are, and never leading to any local changes of any moment, the joint eymptoms are of high importance from their being invariably present, and trom their being usually the first to call attention to a disorder with such disestrous consequences ss rheumatism in childhood.

In many textbooks rheumatism in children is olessified as acute, subacute, and chronic. Such classification must surely be mainly based on the nature of the joint involvement, if it be based on anything at all. Now rheumatism in the child is singularly uniform in its manifestations, there being but little variation in one case from another as regards the severity of the joint troubles, the suddenness of onset, or the degree of pyrexia. This being 80, any division into acute and subacute is to me unnecessary and uncalled for. Even rheumatic fever is a misnomer when applied to rheumatism as ordinarily portrajed in children, in whom attacks presenting the symptoms of the adult type of the complaint are of exceptional rarity. Still less justification can I find for the use of the term "chronic" as applying to rheumatism in children. The joint symptoms rapidly and completely disappear under appropriate treatment, and any remaining effect, such as even a slight temporary stiffness, is wholly exceptionel. Children, too, are free from the vague and annoying nerve-muscular pains, so common in their elders, which are frequently, for no adequate reason, diagnosed as chronic rhenmatism. Any chronic joint affection in the child is, I would say, certainly not rheumatic, and where any joint trouble per. sists, after say three days' treatment with salicylate of sodium, I would be induced to reconsider the diagnosis.

In the treatment I have found the moderate doses of salicylate of sodium ordinarily employed so entirely efficacious that I have never found occasion to use the massive ones adrocated by Dr. Lees.1 With him I quite agree that the drug does more than merely relieve pain and lower temperature, but is in some sense a specific in rheumatism, and I further agree with him that its depressing effects have been exaggerated. But these large doses are apt to cause alarming symptoms akin to 